\title{
Creutzfeldt-Jakob researchers seek greater access to data on cases
}

Paris. Revelations last weekend in the British press that the United Kingdom has identified five new suspect cases of a novel variant of Creutzfeldt-Jacob Disease (CJD) have brought to the boil simmering tension among researchers over when data concerning new suspect cases should be released, either to the public or to other researchers.

The appearance of the new CJD variant, first identified in March, is widely considered as being possibly related to the consumption of beef contaminated with the agent that causes bovine spongiform encephalopathy. The new suspect cases follow 11 that had previously been confirmed in the United Kingdom (see The Lancet, 347, 921; 1996).

The European CJD surveillance network, an informal forum of the national surveillance networks, agreed at a meeting in Edinburgh last month that information on new cases of the novel variant should initially be made public once a month, and perhaps later on a three-monthly basis, if it turns out that this makes more sense in terms of the number of cases being declared.

This approach is endorsed by Robert Will, the head of the CJD Surveillance Unit in Edinburgh, which is supported by the UK Department of Health. "Our intention is to release all the information on a regular basis," he says. "That is how it should be."

But Will also warns that making data available on suspect cases would be "misleading", arguing that many suspect cases turn out not to have CJD at all, much less the novel variant. "It is meaningless to talk about suspect cases," he says, adding that long before the current events, it had been his unit's policy not to disclose details of suspect cases. "My concern is to give accurate information," he says. "There is a lot of speculation about what is happening, and a lot of it is inaccurate."

Will points out, for example, that the original paper on the novel variant of CJD referred to one case with all the symptoms of the variant - the patient died in 1980 at the age of 16 years from CJD-like symptoms - but that this diagnosis was eventually discounted. "I'm reluctant to disclose suspect cases," he says. "If I start saying we have X 'suspect cases', people will say there are X 'cases', and that is very misleading."

Other researchers in the field say that they empathize with Will's concerns about the dangers of misleading the public. But several disagree with the insistence of the Edinburgh surveillance unit not to divulge information on suspect cases. "It's a pity that these five cases appeared in the Sunday Times before I had been informed," says one member of the European CJD network.

Other members of the network agree that there is little point in making public all suspect cases either of CJD, or of its novel variant. Nevertheless they argue that information on 'highly-suspect' cases - for which additional neurological information is available - should be circulated promptly to all researchers working in the field, both in Britain and abroad.

"The United Kingdom has probably already done cerebral biopsies on these five suspect cases," says one European scientist. "But we are still completely in the dark [as to the results]; we still don't know whether these five cases are confirmed or not."

These researchers emphasize the importance of access to new information, even on suspect cases. "If we are going to have an idea of the evolution of the new variant, we need to know its incidence, and the exact dates when cases occurred," says one.

Other researchers point out that science is "a two-way process." France, for example, has had one confirmed case of the new variant of CJD, but has two other highly-suspect cases. French scientists point out that this information has been made available to UK scientists. "They need to know figures from other European countries, especially at this phase of uncertainty," says one CJD researcher.

"We are going to have to hammer out a definition of what is a highly suspect case," says another, adding that agreement is needed that information on such cases will be released in the same way as that on confirmed cases.

Declan Butler

\section{ESA wants compulsory Earth missions}

Munich. Nine teams of European scientists last week presented proposals in a competition organized by the European Space Agency (ESA) to select a new family of scientific Earth observation missions called Earth Explorers - to fly in the first decade of the next century. ESA's 15 member states will choose three or four missions for further study towards the end of the year.

One candidate mission would measure the Earth's magnetic fields at various altitudes and study their influence on the solar wind. Another would measure precisely the Earth's shape, which in turn would allow a better determination of the net ocean circulation. Remote sensing technology would also be used by a further proposed mission to map glaciers, ice sheets and sea ice, yielding data for research into climate change.

ESA's Earth observation programme so far has consisted mainly of operational satellites geared towards commercial users, such as meteorological services, although the stable includes a series of multi-instrumented remote-sensing satellites, ERS-1 and ERS-2, and the planned Envisat satellite. More than half the data from ERS missions go free of charge to over 270 selected research teams (see Nature 374, 665; 1995), on the basis of peer-reviewed competition.

But the idea behind the dedicated family of Earth Explorers is for researchers to be more directly involved in designing instruments to suit their scientific requirements. This 'bottom-up' approach is modelled on

\author{
Earth missions
}

Rough seas: exaggerated sea-levels as recorded by Europe's ERS-1 satellite.

that used in ESA's successful space science programme (see Briefing, page 461).

To reinforce the Earth Explorer programme, ESA also wants its funding to be compulsory for member states, again in line with the space science programme, which is the only mandatory ESA programme.

Providing the Earth Explorer programme with the same financial status as the science programme would ensure guaranteed levels of funding. ESA will put its request to the the space ministers of its member states at a meeting in Brussels next year. Given the tight financial situation which led last year to the capping of the space science programme, however, ESA may find it difficult to win immediate approval for its proposals. Alison Abbott 